\title{
HTA for pharmaceuticals in Europe: will the mountain deliver a mouse?
}

\author{
Livio Garattini ${ }^{1} \cdot$ Anna Padula $^{1}$
}

Published online: 22 August 2019

(c) Springer-Verlag GmbH Germany, part of Springer Nature 2019

JEL Classification I1 $\cdot \mathrm{I} 2 \cdot \mathrm{I} 3$

\section{Introduction}

For at least two decades, health technology assessment (HTA) has been considered worldwide the most comprehensive and suitable approach to support health policy decision making for specific technologies. Many associations have been founded all over the world and the number of publications including it in the title has reached around a thousand in the last decade (Fig. 1).

Although HTA was born in the USA [1], most articles recently have come from other areas, especially the European continent and Canada (Fig. 2). After the very first American definitions of HTA in the late 1970s, many more followed [2-5] —one from the World Health Organization [6]—and an open consultation has been very recently launched to share a single, globally acknowledged definition [7]. According to this proposal, a technology can be a medicine, a test, a device or a procedure, and even a program or system, and the assessment has to be multidisciplinary including clinical, economic, organizational, social, ethical and legal aspects. It may imply different activities related to the lifecycle of the technology (e.g., horizon scanning before launch and re-assessment afterward) [8]. The expected outcomes are recommendations for evidence-based policy-making [9], bridging evidence-based medicine and economic evaluation and including the social, legal and ethical implications.

Here, we try to take stock of the HTA experience in the European Union (EU) over two decades from the first project and then we work out a possible future strategy for pharmaceutical market approval and reimbursement policy in the EU.

Livio Garattini

livio.garattini@marionegri.it

1 CESAV, Centre for Health Economics, Institute for Pharmacological Research Mario Negri IRCCS, 24020 Ranica, Italy

\section{Historical background}

The first move for coordination of HTA in Europe was the EUR-ASSESS project, funded by the European Commission (EC) in the mid 1990s [10], followed by two other projects (again funded by the EC), which led to the establishment in 2006 of EUnetHTA; this large network of organizationsstill currently funded by the EC until 2020 [11] - aims at supporting HTA as a decision-making tool for the EU and its Member States [12]. To help limit misunderstandings, a glossary of HTA adaptation terms was issued in 2009 [13]. Later, to strengthen cooperation among the EU Member States, a formal HTA Network including a representative from each of the EU countries was directly established by the EC and met for the first time in 2013 [10].

In 2016, the EC published an Impact Assessment on HTA in Europe, which recognized the validity of the EUnetHTA Core Model for HTA analyses [10]. The model includes nine 'core domains', which can be split into two groups according to the aspects analyzed [8, 11]: (1) 'technical' (including technical aspects, safety and clinical effectiveness), (2) 'other' (economic, ethical, organizational, social and legal aspects). According to this model, 'rapid HTAs' should be carried out within 6 months, while 'mini HTAs' should provide information for decision making on only four domains (technical, social, organizational and economic) within a few weeks [14].

In 2017, the European Parliament called on the EC to propose legislation on HTA in Europe for assessing the therapeutic value of new technologies (especially of medicines) [15], recommending that future EU rules should be limited to clinical assessment. The EC subsequently released a legislative proposal for HTA regulation in 2018, supporting a European single assessment of relative effectiveness for pharmaceuticals (and certain types of medical devices) through a Member State Coordination Group [5], at the same time leaving pricing and reimbursement decisions to nations. In practice, this would imply devolving 


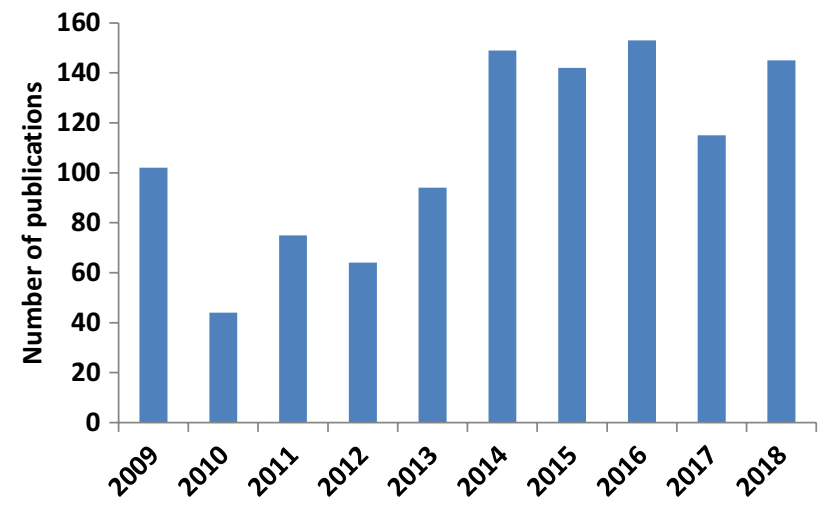

Fig. 1 Articles referring to HTA in the title (2009-2018). We searched the PubMed international database using 'HTA' OR 'health technology assessment' as search terms to select all the articles containing the keywords in their title. From the 1083 articles published in English from January 2009 until December 2018 initially identified, 85 were discarded as not pertinent to the topic. Finally, we identified 546 European articles and analyzed them according to the type of journal

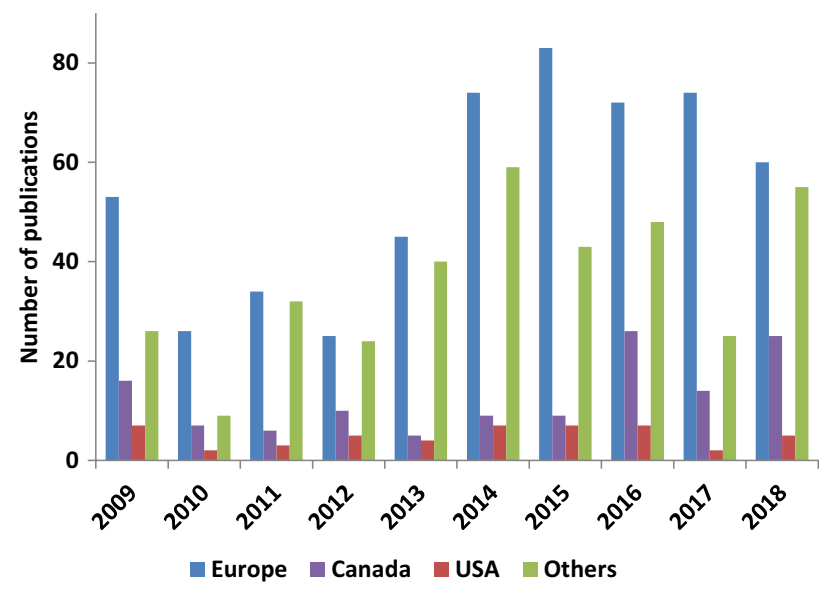

Fig. 2 Articles referring to HTA in the title by geographic area (2009-2018)

the assessment of the first group of more scientific technical and clinical domains to a European body, while Member States would remain responsible for the second group of more context-specific HTA domains [10].

\section{Critical issues}

Metaphorically, HTA can be likened to a 'melting pot' of different disciplines, with experts being mainly epidemiologists, health economists, physicians, and pharmacists, brought together to assess health technologies from the policy makers' viewpoint [16]. The multidisciplinary approach was probably the main factor in its success, regardless of the real contribution of all domains potentially explored. For instance, the contribution of ethical aspects has always been relevant in theory and scant in practice [2, 17-19], with articles on methods often overwhelming those on applications in the literature [20]. The most likely reason is that it is problematic (even impossible) to test ethical implications of single technologies empirically as ethics reports to more general issues [21], e.g., ubiquitous conflicts of interest raised in medicine [22]. Although much less analyzed in the literature, roughly the same holds for legal aspects [19], with the indication not to conduct HTAs on pharmaceuticals close to patent expiry protection as a good example of very general (though not trivial) recommendation [23]. In practice, HTA has always been much more narrowly defined in Europe [2], and the main outcomes have been relative effectiveness and cost effectiveness analyses (respectively, REAs and CEAs) [16], as the distribution of publications by type of journal indirectly confirms (Fig. 3).

REAs of new therapies should compare their benefits and harms to one or more existing interventions [24, 25], by analyzing the first group of the Core Model domains [10], in order to evaluate the clinical relevance of their potentially added therapeutic value compared with the best available treatments [12]. Since randomized clinical trials (RCTs) are unanimously considered the gold standard for assessing both efficacy under ideal conditions and effectiveness in healthcare practice [24, 26-28], they are still the preferred source for REAs together with solid meta-analyses based on homogeneous RCTs [4]. However, robust RCTs designed on hard clinical endpoints (e.g., overall survival for anticancer drugs) are very expensive and sometimes hard to organize [29], so less rigorous studies are often considered when head-to-head RCTs with the comparators of interest are not available [28, 30]. Despite the well-known limits of routine data drawn from administrative and health databases [31], there is now a growing - and fashionable - argument in favor of real-world 'big data' as a cheap and easy alternative to RCTs [32]. More, practical and ethical issues against head-to-head RCTs are often raised for orphan drugs for rare diseases

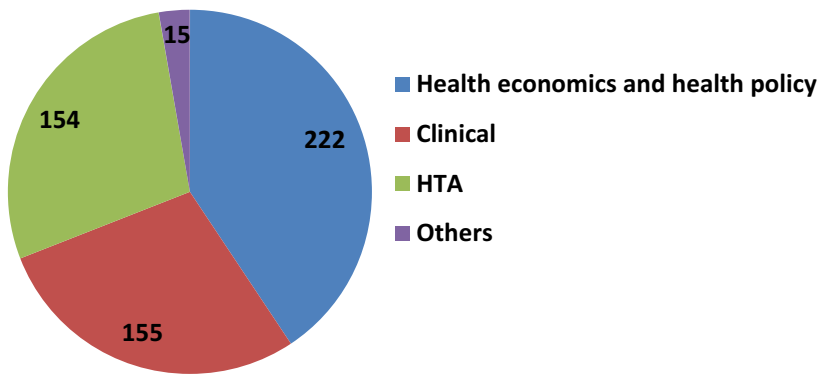

Fig. 3 European articles referring to HTA in the title by type of journal (2009-2018) 
and drugs for life-threatening diseases where preliminary data suggest a positive clinical effect [4]. In addition to (uncontrolled) observational studies and single-arm trials [29], even a new study design has been proposed for REAs, indirectly comparing two treatments on the basis of existing RCT data-referred to as the 'mixed treatment comparison' [27]. However, generating unconfounded evidence from sources other than RCTs remains questionable [26], and all these alternatives may be used to validate or strengthen (rather than substitute) the results of existing RCTs [4]. Although HTA agencies always seek robust methods for REAs of drugs in clinical practice [33], the need of indirect comparisons inevitably arises when no head-to-head RCTs are available [30].

While REAs are based on clinical evidence-which should be global by definition - the main added value of CEAs should be costs, which are dramatically affected by domestic features, like clinical practice patterns and health care system frameworks, so CEA results can hardly be extrapolated from one setting to another [34]. That is why the EC guidance does not recommend European CEAs and leaves these analyses to single countries. CEAs themselves do actually imply a multidisciplinary approach, adding economic and organizational aspects to the clinical ones needed for REAs [34]. In general, CEAs are still a young discipline in healthcare, and there is still disagreement on their methodology so different methods can lead to different results [14]. Yet recent developments have increased the complexity of CEAs at the expense of transparency, making them seem even 'arcane' [35]. In particular, unit costs - one of the two variables needed to make up any cost item together with resource use-can often be only rough proxies of real healthcare costs [34], the mainstay of a CEA. This happens especially for hospital services-by far the main health care expense-when they are sourced from tariffs lists, which is often the case in European CEAs. For instance, in Italy tariff lists originally stem from limited domestic surveys and are seldom updated [36]. In general, health scientists must be fully aware that, differently from measuring clinical variables, any cost estimate is open to discretion and can give very different results depending on the accounting method used [37]; thus, any CEA result should be viewed with caution and any input carefully analyzed in advance.

\section{Policy implications}

After almost three decades of official endorsement, HTA regulation in the EU still has not taken off in practice, and the most encouraging outcome of all the efforts so far still seems to be the collaboration among experts from several disciplines and countries with different expertise [38], involved in well-financed projects throughout Europe. However, never mind whether HTA was originally considered a type of policy research [17] or a user of existing research [14], it was 'sold' to the EU as a reliable tool for health policy decision making [8]. According to the semantic difference between 'scientific assessment' and 'prescriptive appraisal' of technologies [20], with only the latter implying some form of recommendation, the former would have not justified the EU huge investments. Without a real impact on health policy decision making, it is hard to claim that the EU should still fund HTA because of a lack of qualified human resources [39]-e.g., health economists [40]. Yet, to regret that the dominant paradigm has become CEA instead of REA [32], although shareable, seems like just one more argument for a 'never ending story'.

In general, the scientific endorsement of REA compared to CEA is pretty obvious according to the different robustness of their methods [12]. However, we feel that the real crux of the matter of the EU pharmaceutical policy is the present role of the European Medicines Agency (EMA) for market approval [41]. This has been limited from its start to the risk-benefit assessments of efficacy and safety, without including any evaluation of the therapeutic value of new drugs, which is then entirely devolved to the regulatory authorities of each EU State. This evident limit has been further strengthened by the latest EMA tendency to fast-track drugs through 'adaptive licensing'. Once preliminary efficacy and safety have been assessed, the REA is entirely devolved to national authorities.

The underlying strategy is fostered by the (popular) 'political creed' that new drugs have to be made available to patients as soon as possible [42], somehow implicitly attributing an incremental therapeutic value to all of them. The most paradigmatic example is new anticancer drugs [43], whose added benefits vary widely and are often based on weak clinical evidence and surrogate endpoints [44], leading to different decisions at the national level mainly on account of the high degree of clinical uncertainty [45]. In practice, as national HTA agencies increasingly suffer the lack of robust clinical evidence for REAs [10], many regulatory authorities slow down and/or restrict the national reimbursement of new (expensive) drugs approved under these expedited regulatory pathways, because of scientific uncertainty $[26,46]$.

\section{Future prospects}

The never ending 'saga' of HTA in the EU confirms that a common pharmaceutical market is still far off. REAs conducted in parallel on the same drug by national agencies are still common, resulting in duplication of work and 
inefficient use of resources. Without a clear-cut action at the EU level, the current fragmentation will persist, perhaps hampered too by the Member States' fear of losing their sovereignty [42].

The very first priority of European pharmaceutical policy to be addressed is assessment of the added therapeutic value of new pharmaceutical therapies; this task has been further shifted to post-marketing approval because of the present EMA fast-track strategy [41], long on promise and short on delivery. At present, EMA seems to act more and more as a sort of highly specialized secretariat, with a growing number of well-paid employees but no reduction in national workloads as a 'trade-off' [42], a situation hard for the Member States to sustain and govern in the near future.

Unlike some other authors [10], we are not convinced that a new HTA organization would be the right solution for building up common REAs, and not just a further (arguable) duplication of the (expensive) EMA experience. A more sensible strategy might be to invert the current trend at the EMA by strengthening its role and expanding its tasks to include REAs. Since an ideal fast, inexpensive and unbiased study design for REAs simply does not exist [27], the return to head-to-head Phase III RCTs for market approval of most drugs could be highly recommended. This should lead to efficiency gains for national regulatory authorities and multinational pharmaceutical companies [25]. For patients, we wonder why it should be considered more unethical to participate in RCTs designed for comparisons with the best treatment, in order to assess therapeutic added value, than merely to obtain market approval against placebo in non-inferiority studies [47].

To conclude, we believe that this change of strategy could help fill the gap of clinical evidence between market approval and reimbursement of pharmaceuticals throughout countries, limiting domestic negotiations to pricing and budgeting [48]. Here, we put forward a proposal for a step in this direction, so as to really contribute to a common pharmaceutical policy in the EU. The right time to open a practical debate on this issue might be now, after the European elections this year, and to constrain (or even stop?) that on HTA for a long time too.

Funding No sources of funding were used to conduct this study or prepare this manuscript.

\section{Compliance with ethical standards}

Conflict of interest Anna Padula and Livio Garattini have no conflicts of interest that are directly relevant to this article.

\section{References}

1. Garattini, L., Casadei, G.: Health technology assessment: for whom the bell tolls? Eur. J. Health Econ. 9(4), 311-312 (2008)

2. Draborg, E., Gyrd-Hansen, D., Poulsen, P.B., Horder, M.: International comparison of the definition and the practical application of health technology assessment. Int. J. Technol. Assess. Health Care 21(1), 89-95 (2005)

3. Tjørnhøj-Thomsen, T., Hansen, H.P.: Knowledge in health technology assessment: who, what, how? Int. J. Technol. Assess. Health Care 27(4), 324-329 (2011)

4. Griffiths, E.A., Macaulay, R., Vadlamudi, N.K., Uddin, J., Samuels, E.R.: The role of non comparative evidence in health technology assessment decisions. Value Health 20(10), 1245-1251 (2017)

5. Migliore, A.: Towards a regulation of HTA in Europe: the proposal from the European Commission. Expert Rev. Med. Devices 16(1), 1-2 (2019)

6. World Health Organization. Medical devices-Health technology assessment. https://www.who.int/medical_devices/assessment/en/. Accessed June 2019

7. Health Technology Assessment international. Open consultation: updated definition of HTA. https://htai.org/blog/2019/03/20/openconsultation-updated-definition-of-hta/. Accessed June 2019

8. Kristensen, F.B., Lampe, K., Chase, D.L., Lee-Robin, S.H., Wild, C., Moharra, M., Garrido, M.V., Nielsen, C.P., Røttingen, J.A., Neikter, S.A., Bistrup, M.L.: Practical tools and methods for health technology assessment in Europe: structures, methodologies, and tools developed by the European Network for Health Technology Assessment, EUnetHTA. Int. J. Technol. Assess. Health Care 25(Suppl 2), 1-8 (2009)

9. Banta, D.: The development of health technology assessment. Health Policy 63(2), 121-132 (2003)

10. Vella Bonanno, P., Bucsics, A., Simoens, S., Martin, A.P., Oortwijn, W., Gulbinovič, J., Rothe, C., Timoney, A., Ferrario, A., Gad, M., Salem, A., Hoxha, I., Sauermann, R., Kamusheva, M., Dimitrova, M., Petrova, G., Laius, O., Selke, G., Kourafalos, V., Yfantopoulos, J., Magnusson, E., Joppi, R., Jakupi, A., Bochenek, T., Wladysiuk, M., Furtado, C., Marković-Peković, V., Mardare, I., Meshkov, D., Fürst, J., Tomek, D., Cortadellas, M.O., Zara, C., Haycox, A., Campbell, S., Godman, B.: Proposal for a regulation on health technology assessment in Europe-opinions of policy makers, payers and academics from the field of HTA. Expert Rev. Pharmacoecon. Outcomes Res. 19(3), 251-261 (2019)

11. Allen, N., Liberti, L., Walker, S.R., Salek, S.: A comparison of reimbursement recommendations by European HTA agencies: is there opportunity for further alignment? Front. Pharmacol. 8, 384 (2017)

12. Directorate General for Internal Policies. Towards a harmonized EU assessment of the added therapeutic value of medicines. 2015 European Parliament, Brussels. http://www.europarl.europa.eu/ RegData/etudes/STUD/2015/542219/IPOL_STU(2015)54221 9_EN.pdf. Accessed June 2019

13. Rosten, C., Chase, D.L., Hicks, N.J.: Milne R Enhancing understanding: the development of a glossary of health technology assessment adaptation terms. Int. J. Technol. Assess. Health Care 25(Suppl 2), 42-47 (2009)

14. Nielsen, C.P., Funch, T.M., Kristensen, F.B.: Health technology assessment: research trends and future priorities in Europe. J. Health Serv. Res. Policy 16(Suppl 2), 6-15 (2011)

15. European Commission. Proposal for a regulation of the European Parliament and of the council on health technology assessment and amending Directive 2011/24/EU. https://ec.europa.eu/healt h/sites/health/files/technology_assessment/docs/com2018_51fin al_en.pdf (2018). Accessed June 2019 
16. Garattini, L., Padula, A.: Multiple criteria decision analysis in health technology assessment for drugs: just another illusion? Appl. Health Econ. Health Policy 16(1), 1-4 (2018)

17. van der Wilt, G.J., Kievit, W., Oortwijn, W.: The added value of integrate HTA guidance in the work processes of health technology assessment agencies. Int. J. Technol. Assess. Health Care 33(5), 597-598 (2017)

18. Hofmann, B., Oortwijn, W., Bakke Lysdahl, K., Refolo, P., Sacchini, D., van der Wilt, G.J., Gerhardus, A.: Integrating ethics in health technology assessment: many ways to Rome. Int. J. Technol. Assess. Health Care 31(3), 131-137 (2015)

19. Garattini, L., van de Vooren, K., Curto, A.: Regional HTA in Italy: promising or confusing? Health Policy 108(2-3), 203-206 (2012)

20. Refolo, P., Sacchini, D., Brereton, L., Gerhardus, A., Hofmann, B., Lysdahl, K.B., Mozygemba, K., Oortwijn, W., Tummers, M., van der Wilt, G.J., Wahlster, P., Spagnolo, A.G.: Why is it so difficult to integrate ethics in Health Technology Assessment (HTA)? The epistemological viewpoint. Eur. Rev. Med. Pharmacol. Sci. 20(20), 4202-4208 (2016)

21. Lysdahl, K.B., Oortwijn, W., van der Wilt, G.J., Refolo, P., Sacchini, D., Mozygemba, K., Gerhardus, A., Brereton, L., Hofmann, B.: Ethical analysis in HTA of complex health interventions. BMC Med. Ethics 17, 16 (2016)

22. Garattini, L., Padula, A.: Conflict of interest disclosure: striking a balance? Eur. J. Health Econ. 20(5), 633-636 (2019)

23. Widrig, D., Tag, B.: HTA and its legal issues: a framework for identifying legal issues in health technology assessment. Int. J. Technol. Assess. Health Care 30(6), 587-594 (2014)

24. Pavlovic, M., Teljeur, C., Wieseler, B., Klemp, M., Cleemput, I., Neyt, M.: Endpoints for relative effectiveness assessment (REA) of pharmaceuticals. Int. J. Technol. Assess. Health Care 30(5), 508-513 (2014)

25. Kleijnen, S., Toenders, W., de Groot, F., Huic, M., George, E., Wieseler, B., Pavlovic, M., Bucsics, A., Siviero, P.D., van der Graaff, M., Rdzany, R., Kristensen, F.B., Goettsch, W.: European collaboration on relative effectiveness assessments: what is needed to be successful? Health Policy 119(5), 569-576 (2015)

26. Bouvy, J.C., Jonsson, P., Longson, C., Crabb, N., Garner, S.: Health technology assessment in the context of adaptive pathways for medicines in Europe: challenges and opportunities. Clin. Pharmacol. Ther. 100(6), 594-597 (2016)

27. Eichler, H.G., Thomson, A., Eichler, I., Schneeweiss, S.: Assessing the relative efficacy of new drugs: an emerging opportunity. Nat. Rev. Drug Discov. 14(7), 443-444 (2015)

28. Angelis, A., Lange, A., Kanavos, P.: Using health technology assessment to assess the value of new medicines: results of a systematic review and expert consultation across eight European countries. Eur. J. Health Econ. 19(1), 123-152 (2018)

29. Kanavos, P., Angelis, A., Drummond, M.: An EU-wide approach to HTA: an irrelevant development or an opportunity not to be missed? Eur. J. Health Econ. 20(3), 329-332 (2019)

30. Lebioda, A., Gasche, D., Dippel, F.W., Theobald, K., Plantör, S.: Relevance of indirect comparisons in the German early benefit assessment and in comparison to HTA processes in England, France and Scotland. Health Econ. Rev. 4(1), 31 (2014)

31. Stevens, A.J., Raftery, J., Roderick, P.: Can health technologies be assessed using routine data? Int. J. Technol. Assess. Health Care 21(1), 96-103 (2005)

32. Banta, H.D.: Perspective: some conclusions from my life in health technology assessment. Int. J. Technol. Assess. Health Care 34(2), 131-133 (2018)
33. Makady, A., Ham, R.T., de Boer, A., Hillege, H., Klungel, O., Goettsch, W.: Policies for use of real-world data in Health Technology Assessment (HTA): a comparative study of six HTA agencies. Value Health 20(4), 520-532 (2017)

34. Garattini, L., Padula, A.: Dutch guidelines for economic evaluation: 'from good to better' in theory but further away from pharmaceuticals in practice? J. R. Soc. Med. 110(3), 98-103 (2017)

35. Brousselle, A., Lessard, C.: Economic evaluation to inform health care decision-making: promise, pitfalls and a proposal for an alternative path. Soc. Sci. Med. 72(6), 832-839 (2011)

36. Garattini, L., Curto, A., Padula, A., Freemantle, N.: Real-world evidence in economic evaluations: really realistic? J. R. Soc. Med. 109(11), 404-407 (2016)

37. Garattini, L., Padula, A.: Comment on: 'The impact of hospital costing methods on cost-effectiveness analysis: a case study'. Pharmacoeconomics (2019). https://doi.org/10.1007/s40273-01900823-3

38. Banta, D., Kristensen, F.B., Jonsson, E.: A history of health technology assessment at the European level. Int. J. Technol. Assess. Health Care 25(Suppl 1), 68-73 (2009)

39. Lampe, K., Schnell-Inderst, P.: INTEGRATE-HTA: the perspective of EUnetHTA. Int. J. Technol. Assess. Health Care 33(5), 605-608 (2017)

40. Cheung, K.L., Evers, S.M.A.A., De Vries, H., Levy, P., Pokhrel, S., Jones, T., Danner, M., Wentlandt, J., Knufinke, L., Mayer, S., Hiligsmann, M.: Most important barriers and facilitators of HTA usage in decision-making in Europe. Expert Rev. Pharmacoecon. Outcomes Res. 18(3), 297-304 (2018)

41. Garattini, L., Curto, A.: European Medicines Agency: leave the UK but remain the same? J. R. Soc. Med. 109(9), 324-325 (2016)

42. Curto, A., van de Vooren, K., Garattini, L.: Market approval for drugs in the EU: time to change direction? Eur. J. Health Econ. 18(8), 933-936 (2017)

43. Garattini, L., Padula, A.: Precision medicine and monoclonal antibodies: breach of promise? Croat. Med. J. 60(3), 284-289 (2019)

44. Salas-Vega, S., Iliopoulos, O., Mossialos, E.: Assessment of overall survival, quality of life, and safety benefits associated with new cancer medicines. JAMA Oncol. 3(3), 382-390 (2017)

45. Kleijnen, S., Lipska, I., Leonardo Alves, T., Meijboom, K., Elsada, A., Vervölgyi, V., d'Andon, A., Timoney, A., Leufkens, H.G., De Boer, A., Goettsch, W.G.: Relative effectiveness assessments of oncology medicines for pricing and reimbursement decisions in European countries. Ann. Oncol. 27(9), 1768-1775 (2016)

46. Vreman, R.A., Bouvy, J.C., Bloem, L.T., Hövels, A.M., MantelTeeuwisse, A.K., Leufkens, H.G.M., Goettsch, W.G.: Weighing of evidence by health technology assessment bodies: retrospective study of reimbursement recommendations for conditionally approved drugs. Clin. Pharmacol. Ther. 105(3), 684-691 (2019)

47. Garattini, S., Bertelè, V.: How can we regulate medicines better? BMJ 335(7624), 803-805 (2007)

48. Garattini, L., Padula, A.: Pharmaceutical pricing conundrum: time to get rid of it? Eur. J. Health Econ. 19(8), 1035-1038 (2018)

Publisher's Note Springer Nature remains neutral with regard to jurisdictional claims in published maps and institutional affiliations. 